\title{
Las traducciones al catalán de la poesía de Wordsworth y Coleridge
}

JOSEP MARCO

Universitat Jaume

\author{
Fecha de recepción: 18 de febrero de 2009 \\ Fecha de aceptación: 15 de abril de 2009
}

Resumen: Este trabajo pretende dar cuenta de las traducciones al catalán de la obra poética de los dos principales poetas lakistas, Wordsworth y Coleridge. En tanto que inspiradores de una nueva sensibilidad poética, su obra ha suscitado un interés constante en el ámbito catalanoparlante desde las primeras décadas del siglo Xx hasta la actualidad. Los primeros exponentes de dicho interés fueron Joaquim Folguera y Josep Maria López-Picó, en el seno del movimiento noucentista; pero quien mayores esfuerzos dedicó a verter al catalán a los dos románticos ingleses fue Marià Manent, por lo cual su obra ocupa un lugar central en este artículo. Después de Manent, Wordsworth y Coleridge fueron traducidos por el poeta ibicenco Marià Villangómez y, más recientemente, por Francesc Parcerisas y Miquel Desclot. En relación con todos estos traductores, pero de modo especial en el caso de Manent, se ha intentado señalar sus afinidades con los poetas que traducían y describir a grandes rasgos sus criterios de traducción.

Palabras clave: Poesía traducida, catalán

Abstract: This article aims to provide an account of the Catalan translations of poetry written by Wordsworth and Coleridge, the two main Lakist poets. Insofar as they inspired a new poetic sensibility, their work has steadily aroused interest in the Catalan-speaking area since the earliest decades of the twentieth century. Their earliest translators were Joaquim Folguera and Josep Maria López-Picó, within the noucentista movement. But it was Marià Manent that invested most effort to translate the poetic work of both English Romantics, and holds, as a result, a central position in the present article. After Manent, Wordsworth and Coleridge were translated by the Ibizan poet Marià Villangómez and, more recently, by Francesc Parcerisas and Miquel Desclot. An attempt has been made to identify the translators' affinities with the poets they were translating and to broadly describe the criteria underlying their translations - Manent receiving more attention than the rest.

Key words: Translated poetry, catalán

INTRODUCCIÓN

La poesía de William Wordsworth y Samuel Taylor Coleridge es uno de aquellos golpes de timón que dejan una estela larga y profunda en las aguas de una literatura cada vez más internacionalizada. Es bien sabido que las Lyrical Ballads, publicadas por primera vez en 1798, suponen un 
alejamiento deliberado y explícito de la retórica y la poética dieciochescas materializadas en un sistema estable de subgéneros poéticos y en una dicción propia para la poesía, es decir, en un registro estrictamente poético, así como una propuesta de nuevos temas y de un nuevo lenguaje. "Es honrada característica de la Poesía que sus asuntos se encuentran en todos los temas que pueden interesar al intelecto humano. La prueba de este hecho ha de buscarse, no en los escritos de los Críticos, sino en aquellos de los propios Poetas" (Wordsworth y Coleridge 1990: 107): así empieza diciendo la "Advertencia" que encabeza la edición de 1798, en lo que constituye una de sus varias declaraciones programáticas. De hecho, sin solución de continuidad, encontramos otra: "La mayoría de los poemas que siguen han de considerarse como experimentos. Fueron escritos principalmente con la intención de probar hasta qué punto el lenguaje de la conversación de las clases medias y bajas de la sociedad se adapta a los propósitos del deleite poético" (ibidem). Toda la experiencia humana como tema potencial y el lenguaje coloquial como referente estilístico, pues: he aquí encapsuladas las líneas maestras de una nueva poética. A partir de este momento, y en consonancia con las propuestas similares que ya habían empezado a formular los románticos alemanes, dichas líneas marcarían (por decirlo en términos de Pascale Casanova 1990) el meridiano de Greenwich literario, al cual habría que ajustar el reloj literario de la modernidad.

En el ámbito catalano-parlante, cuando se publicaron las Lyrical Ballads ese reloj llevaba un retraso de siglos y hasta se podría decir que estaba prácticamente parado. Los historiadores de la literatura catalana han convenido en situar en 1833, con la publicación de la "Oda a la patria" de Aribau, el arranque de la llamada Renaixença, o resurgir de las letras catalanas tras tres largos siglos de decadencia que siguieron a la época de esplendor medieval. Así pues, la eclosión del romanticismo no encuentra todavía un terreno abonado en la literatura catalana del momento, a pesar de que el despertar de muchas naciones europeas durante el siglo XIX hunde sus raíces en el espíritu romántico (Casanova 1999: 108-113). Como afirma Molas (1965: 13), "[n]uestros poetas, pues, no conocieron a los grandes románticos nórdicos, de Wordsworth y Coleridge a Heine", ${ }^{1}$ lo cual, por otra parte, tampoco es demasiado insólito si se tiene en cuenta que, como afirma Pegenaute (2004: 381) respecto a la literatura española, "[e]n cuanto a Wordsworth y Coleridge [...] no hallamos eco alguno, aparte de comentarios dispersos, como los presentados por Alcalá Galiano", si bien

\footnotetext{
${ }^{1}$ La traducción de citas procedentes de obras escritas originalmente en catalán o en inglés (si no se indica lo contrario) es mía.
} 
constata que "se había publicado El viaje del marino, de Coleridge, en versión de un tal B. Archer" (ibidem) antes de finalizar el siglo XIX.

\section{LOS PIONEROS: JOAQUIM FOLGUERA Y JOSEP MARIA LÓPEZ-PICÓ}

El introductor de los poetas lakistas (incluido Southey) en las letras catalanas parece haber sido el poeta y traductor Joaquim Folguera. En la antología Traduccions i fragments (1921) se incluyen poemas traducidos del francés y del inglés, y entre estos últimos figuran tres poemas de Wordsworth (dos titulados genéricamente "Cançó" y un tercero con el título de "Març") y una parte sustancial de "The Rime of the Ancient Mariner", bajo el título de "La complanta del vell mariner", que comprende los cuatro primeros cantos del poema así como la primera estrofa del quinto (en total, la mitad del poema, aproximadamente). Las dos canciones hablan de la muerte y de lo efímero de la belleza, mientras que "Març" es una celebración del final del invierno, de la retirada de la nieve (comparada con un ejército en desbandada) y de la irrupción del azul del cielo entre nubes que se alejan. Estos tres poemas exhiben cierto gusto arcaizante tanto en el léxico como en la morfología verbal y una clara voluntad formalizadora, ya que el discurso es metrificado y rimado. Quizá el mejor exponente del arte versificador de Folguera sea el poema "Març", en el que el uso sistemático del heptasílabo se alía con un esquema de rima muy eficaz para dotar al texto de una gran musicalidad, inseparable del tono de celebración al que aludíamos hace un momento". En cambio, el fragmento del "Ancient Mariner" no se somete a ningún patrón métrico ni utiliza tampoco la rima, por lo que la estrofa de la balada del original se convierte en una especie de prosa recortada sin un ritmo recurrente. Más adelante veremos de qué modo contrasta esta opción traductora con la adoptada por Marià Manent.

Los tres poemas de Wordsworth y el extenso pasaje de "The Rime of the Ancient Mariner" traducidos por Folguera vieron la luz por primera vez en "La Revista" en 1916 y 1917, respectivamente. El impulsor de esta importante publicación periódica, lanzada en 1915, fue Josep Maria LópezPicó, a cuyos esfuerzos se debe también la publicación (póstuma, puesto que Folguera murió en 1919) del volumen mencionado en el párrafo anterior, Traduccions $i$ fragments (1921). Folguera y López-Picó fueron amigos, además de colaboradores literarios, por lo que no es de extrañar que su interés por los primeros románticos ingleses fuese compartido. Así,

\footnotetext{
${ }^{2}$ De manera bien curiosa y llamativa, pues contrasta vivamente con el acierto general de la traducción, en este tercer poema se incurre en un error de sentido que contradice el movimiento general del texto, ya que el último verso, que exulta con el cese de la lluvia ("The rain is over and gone!"), es traducido como "la pluja és damunt i cau" ('la lluvia está encima y cae'), algo difícilmente compatible con los claros que se han abierto en el cielo y con la afirmación de que "El cel és blau" ('El cielo es azul').
} 
en el volumen Temes: exercicis de geografia lírica (López-Picó 1928) encontramos las traducciones de un poema de Wordsworth (la primera de las "canciones" que había traducido Folguera pocos años antes) y de otro de Coleridge. El de Wordsworth, aquí titulado "Tema melangiós de Wordsworth" ('Tema melancólico de Wordsworth') es un intento más que notable de recrear la musicalidad de la balada inglesa en versos heptasílabos, una opción sin duda arriesgada que aquí da un fruto brillante. El de Coleridge, titulado "Al-legoria coleridgiana del temps real i el temps imaginari", muestra la misma solvencia técnica pero con alguna desviación importante del sentido, como el hecho de omitir que el chico que corre tras su hermana en la llanura que corona la montaña es ciego, elemento sin duda importante en la alegoría.

Tanto Folguera como López-Picó se inscriben en el movimiento noucentista, del cual hablaremos con mayor detalle en el siguiente apartado.

\section{LA FIGURA SINGULAR DE MARIÀ MANENT}

Si bien el resultado de los esfuerzos de Folguera y López-Picó es meritorio en muchos sentidos, el mayor divulgador de Wordsworth y Coleridge, así como de otros poetas románticos ingleses (entre los cuales su preferido era sin duda Keats), en Cataluña fue Marià Manent. Manent publicó a lo largo de su vida tres antologías de poesía traducida del inglés: Versions de l'anglès (1938), publicada gracias al empeño de tres poetas a la sazón aún jóvenes (Teixidor, Rosselló-Pòrcel y Vinyoli) por la Residencia de Estudiantes de Barcelona; Poesia anglesa i nord-americana (1955), publicada en la editorial Alpha en plena dictadura franquista; y El gran vent $i$ les heures (1983), una segunda edición ampliada de Versions de l'anglès, publicada nada menos que cuarenta y cinco años antes. Las tres antologías incluyen traducciones que habían aparecido previamente en publicaciones periódicas, así como otras inéditas, y en las tres encontramos versiones de poemas de Wordsworth y Coleridge.

\subsection{La afinidad poética entre Marià Manent y los poetas lakistas (Wordsworth y Coleridge) \\ Manent se acerca a estos dos poetas por afinidad estética, es decir, porque percibe una serie de bases poéticas compartidas. Manent da sus primeros pasos literarios en pleno auge del llamado noucentisme, un movimiento de amplio espectro político y cultural que pretendía (simplificando mucho, claro está), por una parte, afirmar la identidad catalana, y por otra, equiparar la cultura catalana al resto de culturas europeas. En el terreno de la literatura, la estrategia noucentista pasa necesariamente por la traducción, ya que una de las prioridades de sus}


ideólogos (con Josep Carner, gran poeta y también traductor, a la cabeza) es la incorporación a las letras catalanas de los grandes nombres de la literatura universal, con el fin de recuperar en la medida de lo posible el tiempo perdido y de llenar las enormes lagunas existentes en una literatura cuya tradición se había visto interrumpida largo tiempo. Además, como han puesto de manifiesto diversos estudiosos (por ejemplo, Ortín 1996, Pericay y Toutain 1996, Toutain 1997 o Sellent 1998), la traducción sirve también para poner a prueba y promocionar un determinado modelo de lengua, o conjunto de preferencias estilísticas en el ámbito de la lengua literaria. Manent hace suyo este programa y, vista la asiduidad con la que se dedica a la traducción poética, no lo abandona en toda su vida. Por otra parte, la orientación ideológica general del noucentisme era catalanista (lógicamente), conservadora y cristiana, y Manent ve reflejada su personalidad en esos valores, con la diferencia de que su catolicismo es probablemente más ortodoxo y tiene menos fisuras que el de otros miembros del movimiento.

Cuando el noucentisme empieza a perder fuerza, de manera manifiesta a partir de la década de los veinte, se atisban los primeros brotes de lo que se dio en llamar post-simbolismo (Marrugat 2009: 22), un intento de "superar los callejones sin salida en los que había caído el simbolismo" (ibidem) que parte de algunos sectores de la vanguardia francesa. Manent se adhiere a esta tendencia, que en realidad no se opone al noucentisme del que procedía el poeta traductor, aunque sí es más puramente poética, más desprovista de connotaciones políticas. En realidad, el post-simbolismo le ofrece a Manent la oportunidad de superar las tensiones y dicotomías propias tanto del simbolismo como del modernismo encarnado por figuras como las de Eliot o Pound, en el mundo anglosajón. Si pensamos en un poema como The Waste Land, por ejemplo, nos damos cuenta en seguida de que su carácter fragmentario no es más que un reflejo icónico de la fragmentación que a su vez caracteriza la condición del hombre moderno, tanto en su vertiente individual como en la social. El ser humano, en el mejor de los casos, atesora los fragmentos e intenta dotarlos de sentido. Pues bien, el post-simbolismo (y Manent en particular) busca la unidad de la conciencia humana (que puede recibir nombres diversos, como alma o espíritu) y la armonía con aquello que la rodea. Este impulso, que en su caso, además, tiene raíces religiosas, enlaza directamente con la poesía de los primeros románticos ingleses, y aquí es donde radica parte de la atracción que éstos ejercen sobre nuestro poeta. ${ }^{3}$

\footnotetext{
3 Terry (1990: 122) subraya "la predilección invariable que Manent sentía por los poetas románticos ingleses". Por otra parte, según Roser i Puig (1998: 15), Manent, en un artículo escrito en sus últimos años, explica que, cuando tenía veinte años, Josep Carner le recomendó
} 
Un aspecto estrechamente relacionado con el anterior, y también compartido por Wordsworth y Manent, es la importancia atribuida a la infancia como crisol de experiencias que alimentan la vida adulta y que reflejan un estado anterior de mayor pureza espiritual. Como pone de manifiesto el poema "Intimations of Immortality from Recollections of Early Childhood", el alma humana, cuando llega al mundo, viene de la eternidad, por lo que es en la infancia cuando se encuentra más cerca de su fuente, de su gloria, de su estado más puro y unitario. Manent, que incluye este poema en su antología de poesía traducida de 1955, escribió y tradujo poemas para niños; además, Marrugat, al referirse al valor que tenía para Walter de la Mare la poesía para niños (valor que no pasó desapercibido, evidentemente, a Manent), afirma lo siguiente (2009: 34):

La operación de De la Mare, pues, es heredera de la de Wordsworth: utilizar la forma poética como vía de recuperación de una visión del mundo no mediatizada por la experiencia, que automatiza la percepción del entorno haciendo que, en lugar de captarlo directamente, se nos haga invisible bajo las abstracciones que hemos hecho de él a lo largo de la vida. Esto lo lleva a recuperar en su poesía la visión siempre sorprendida, renovada y amable del entorno que tienen los niños o los animales típicos de la literatura infantil; y a ser un poeta de dicción y pensamiento absolutamente cercanos a Manent y defendido ardientemente en los artículos de éste.

Aparte de los rasgos mencionados, que tienen que ver con la visión del mundo, hay que mencionar otro aspecto compartido entre Manent y Wordsworth y Coleridge que desempeña un papel central en sus respectivas poéticas: la importancia atribuida a la forma y, más concretamente, la preferencia por las formas métricas y estróficas populares. En cuanto a la forma, Wordsworth dedica mucho espacio en su famoso prefacio a la edición de 1800 de las Lyrical Ballads a explicar por qué escribe en verso, habida cuenta de que renuncia a otros atributos de la poesía de su tiempo, como la llamada dicción poética. Quizá la razón más poderosa, aunque no la más extensamente desarrollada ni la enumerada en primer lugar, sea la de que el metro permite a la inteligencia humana percibir similitud en la disimilitud en virtud de la repetición de un mismo patrón rítmico. A esta actividad se le asigna una gran relevancia en el quehacer intelectual del ser humano; además, dicha percepción produce placer, y el placer está en la base de los otros argumentos esgrimidos a favor del metro: que dota de pasión y sentimiento al lenguaje cuando éste

que leyera los ensayos de Hazlitt en The Spirit of the Age, y señala que los que más le interesaron fueron los referentes a Wordsworth y a Coleridge. 
no alcanza las cotas adecuadas al objeto del que se ocupa, y que atempera y mitiga el dolor que puede provocar la contemplación del sufrimiento humano a través del lenguaje. Pues bien, la misma consideración positiva le merece a Manent el metro y los demás recursos fónicos de la poesía. Según Marrugat (2009: 48), "Manent pone mucho énfasis en la forma poética como parte esencial de la poesía en tanto que es un campo de ésta con significado y en tanto que sitúa al poema en la tradición y, por lo tanto, lo convierte en poesía". Más adelante, el mismo Marrugat se hace eco de unas palabras del prólogo a Poesia anglesa i nord-americana según las cuales (2009: 61) una "base métrica" determinada es "el elemento unificador de las versiones aquí recogidas". Y, por si hiciera falta mayor explicitud, en la reseña de la traducción de tres poemas de Wordsworth realizada por Miquel Desclot (traducción de la cual nos ocuparemos más adelante), Manent (2009: 151) elogia sin reservas la inclusión en el libro traducido del prólogo de las Lyrical Ballads por constituir una "bella defensa de la métrica".

En cuanto a la predilección por las formas estróficas populares, Marrugat (2009: 14) afirma que Manent encontró en diversos autores de lengua inglesa (entre los que cita a Burns, Yeats y De la Mare) "el uso de estrofas populares breves, musicales y de lenguaje sencillo pero cargado de las infinitas significaciones que le ha otorgado su aparición recurrente en la tradición literaria". Aunque Wordsworth y Coleridge no son mencionados, conviene recordar que fueron ellos quienes revitalizaron la estrofa de la balada tradicional, que había caído en desuso en la poesía culta, y que la utilizaron en muchos de los poemas que componen las Lyrical Ballads (el título ya lo dice todo) y de modo especialmente notorio en la "Rime of the Ancient Mariner", traducida íntegramente por Manent. Esta preferencia por lo popular, como ya se ha visto más arriba, no afecta sólo a las formas poéticas, sino que viene de más abajo, del mismo léxico en el que, según la concepción de Wordsworth, debe expresarse la poesía. Entre otras cosas, el prólogo de 1800 es un alegato a favor del uso con fines poéticos del lenguaje hablado realmente por los seres humanos, especialmente en un ambiente rural, donde las palabras están más cerca de la naturaleza y hablan sin la afectación propia de la vida social urbana. Concomitantemente, es también un rechazo explícito de la dicción poética. Manent, por su parte, también se opone al carácter abstruso que revisten muchos de los poemas que se publican en su época y defiende un lenguaje "sencillo, depurado y sin turbulencias" (Marrugat 2009: 19). Terry, por su parte, nos habla de la "preferencia que tenía por el 'sentimiento contenido, expresado en palabras simples y claras' que creía encontrar en la poesía inglesa, igual que en la china" (1990: 122). 


\subsection{El "método" de traducción: apropiación versus fidelidad}

Por otro lado, y más allá de las afinidades entre la poética de Manent y la de los románticos ingleses de la primera generación, ${ }^{4}$ diversos autores han subrayado el papel que desempeña su propia concepción de la poesía como criterio rector no ya de las elecciones, sino también del estilo que muestran sus traducciones. En el prólogo a su Obra poètica, publicada en 1956, Manent no distingue entre obra poética propia y poesía traducida porque "mis modestos ensayos de interpretación de líricos extranjeros me parecen inseparables de los versos propios"; sin embargo, en la Poesia completa, de 1986, no incluye sus versiones de poesía china porque considera que no se debe confundir la obra propia con lo que no pasa de ser "un simple fenómeno de compenetración". Sea como fuere, y más allá del criterio del propio poeta-traductor, varios autores han considerado que, por debajo de las traducciones y versiones de Manent, late una clara voluntad de apropiación de aquello que traduce. Según esta consideración, lo que oímos en estas traducciones no es la voz del poeta extranjero, sino la del propio Manent, que toma un poema ajeno como pretexto para expresarse. Quien más abiertamente defiende esta tesis es Desclot (1988), quien, por una parte, señala que no son habituales casos como el de Manent, en los que la poesía traducida supera en volumen la obra poética original, y, por otra, añade que "la obra poética traducida de Manent parece surgir de una necesidad personal completamente comparable a la necesidad que propicia el nacimiento de un poema original. Lo cual, en consecuencia, equipara los resultados de la traducción a los de la creación original misma" (1988: 39). Desclot se atreve incluso a lanzar una conjetura sobre los posibles motivos de este hecho al decir que "no debe encontrar en sí mismo la materia y el impulso necesarios para la escritura de obra original, y [...] por lo tanto los busca fuera, en los poetas de otra lengua". Marrugat, por su parte, no ve motivos para trazar fronteras demasiado nítidas entre poesía traducida, obra poética propia e, incluso, actividad crítica, ya que en los tres ámbitos prevalece la misma estrategia (2009: 1011):

A nivel colectivo, para Manent la traducción es una forma de construir una tradición literaria propia, como también hacen la crítica y la creación literarias; a nivel personal, es, también como la crítica y la creación, una vía de construcción de una poética y de defensa de unos

\footnotetext{
${ }^{4}$ Roser i Puig (1998: 19) enumera de modo bien sintético y comprehensivo los valores del romanticismo inglés que Manent "discute y define con mayor frecuencia": "la importancia de la Naturaleza; las cuestiones relacionadas con la forma y la dicción poética; el tema de la infancia y la inocencia; el valor poético de la fantasía, la imaginación y el misterio, y el papel del poeta como individuo".
} 
valores —estéticos y morales- que se quieren predominantes en la propia sociedad.

La aceptación de que una de las prioridades de Manent al traducir poesía extranjera es que, a través de ella, se oiga su propia voz trae aparejada una consecuencia estilística inevitable: que las traducciones se parecerán más entre sí y a la obra poética propia del traductor que a los respectivos poemas originales de los que derivan. Desclot, para referirse a este efecto de los textos sobre el lector, habla de "homogeneización del lenguaje poético de los diferentes autores" (1988: 42) y lo ilustra de un modo bien gráfico (ibidem):

El Wordsworth de Manent, por ejemplo, no suena muy diferente de su Byron, bien al contrario de lo que ocurre con los originales respectivos; del mismo modo, Blake llega a parecer poco alejado de Keats, por citar un poeta a quien evidentemente no se parece mucho. La explicación, insisto, es para mí la misma, tan simple, que vengo dando desde el principio: quien nos está hablando a través de las máscaras de Wordsworth, de Byron, de Blake o de Keats es el poeta Marià Manent, que ha necesitado encarnarse en la palabra de otro para hacerse real y aprehensible.

Por su parte, Marrugat (2009: 46-47) atribuye la uniformidad de los esfuerzos traductores de Manent en Versions de l'anglès no sólo al hecho de proceder de la misma mano, sino también, de modo fundamental, a la elección misma, puesto que, afirma (ibidem), "Manent busca los elementos permanentes de la poesía bajo su mutabilidad temporal, busca el mínimo común denominador para unificar su diversidad", y al mismo tiempo deja fuera de la antología otros poemas o fragmentos que habrían hecho menguar la coherencia del conjunto por pertenecer a otras líneas de la tradición.

Sin embargo, no todos los estudiosos de la poesía traducida de Manent están de acuerdo en el predominio de la apropiación como método o criterio rector de su actividad traductora. Terry (1990: 117-118), en un intento de situar el caso concreto en unas coordenadas más generales, realiza la siguiente distinción básica:

se puede hacer una distinción aproximativa entre dos clases de traductor: el poeta -él mismo poseedor de un estilo distintivo que apenas se deja disimular- que intenta apropiarse el original, transponiéndolo a su propio idioma poético, y aquel otro poeta que, con unas dotes técnicas quizá en absoluto inferiores, sabe reconocer el carácter único del poema que quiere traducir y que emplea todas sus fuerzas en transmitir las cualidades del original a través de su 
propia lengua. [...] Manent [...] pertenece evidentemente a la segunda: al tipo de traductor que se siente responsable, en primer lugar, ante el poeta original, cuya obra se le presenta como un estímulo directo a sus propios talentos poéticos.

Aunque algunos de los ejemplos que aduce Terry parecen demostrar la hipótesis contraria a la que él defiende, como en el caso de un poema de Emily Dickinson (Terry 1990: 121), otros son bien elocuentes y parecen darle claramente la razón: por ejemplo, cuando se refiere a la traducción de un poema de Dylan Thomas (1990: 127-128). Terry (1990: 123-124) destaca "la sensibilidad con la que Manent ha sabido adaptar su propia lengua a una enorme variedad de estilos poéticos", que deriva de "la capacidad que demuestra no sólo de volver a imaginar la génesis de un poema determinado, sino también de reproducir, hasta donde le sea posible, la misma manera en que éste viene a desplegarse dentro de la mente del lector".

Lo que esta disparidad de opiniones pone de manifiesto es un déficit en el estudio de la obra traductora íntegra de Manent, ya que todos los estudiosos basan sus afirmaciones en poemas aislados o en una consideración parcial del corpus 'manentiano'. Aquí me abstendré de entrar en este debate, que nos llevaría demasiado lejos, por cuanto la distinción que establece Terry es tan antigua como la misma reflexión sobre la traducción. Sin embargo, a modo de síntesis, cabe decir que los dos extremos de la apropiación y la fidelidad quizá no sean del todo irreconciliables: de vez en cuando, gracias a una feliz conjunción de talentos y sensibilidades, el traductor (casi) puede obrar el milagro de servir a dos amos a la vez. Puede que sea eso lo que quiere decir Parcerisas (1989: 18) mediante la elocuente metáfora del velo, a propósito de las versiones de Manent:

El estudio y la traducción han ido siempre acompañados de una intuición afín, es decir, de una reciprocidad con los autores traducidos, y esta afinidad, como era de esperar, llega a convertirse en un velo umbrío e imperceptible, en una especie de gasa muy tenue, que nos filtra la voz original con tanta gracia que parece volverla genuinamente catalana, sobre todo en aquellos autores que tienen una sensibilidad más semejante a la suya.

En este trabajo no podemos detenernos en un análisis minucioso ni siquiera de las traducciones de poemas de Wordsworth y Coleridge, pero sí intentaremos ilustrar algunos de los aspectos que, como se ha visto más arriba, han identificado los estudiosos. Para ello, nos centraremos en los poemas de ambos románticos incluidos en la antología Poesia anglesa $i$ 
nord-americana (1955), que, en opinión de Terry (1990: 118), es el "libro central como traductor" de Marià Manent.

\subsection{Wordsworth y Coleridge en Poesia anglesa i nord-americana (1955)}

Dicha antología contiene los siguientes poemas de Wordsworth: "En el pont de Westminster" ("Composed upon Westminster Bridge, September 3, 1802"), "Llúcia" ("Poems founded on the affections", VIII y "Poems of the imagination", XI), cuatro fragmentos de "El Preludi" (The Prelude), "Pur element de l'aigua" ("Miscellaneous Sonnets", XXXIII), "Oh rossinyol!" ("Poems of the Imagination", IX), "El barranc encantat" ("The faery chasm"), "Rectoria al comtat d'Oxford" ("A parsonage in Oxfordshire"), "Cementiri al sud d'Escòcia" ("A place of burial in the South of Scotland") y "Clarianes d'immortalitat en els records de la primera infantesa" ("Intimations of immortality from recollections of early childhood"). Además, también se incluyen los siguientes poemas de Coleridge: "Gel a mitjanit" ("Frost at midnight"), "El rossinyol" ("The nightingale"), un fragmento de "Kubla Khan" ("Kubla Khan"), "Cançó de Glicina" ("Song", de Zapolya), "El record" ("The keepsake"), "Inscripció per a una font d'un bruguerar" ("Inscription for a fountain on a heath") y "Poema del vell mariner" ("Rime of the Ancient Mariner").

\subsubsection{Wordsworth}

En "Composed upon Westminster Bridge...", Wordsworth ensalza la belleza de Londres cuando la ciudad todavía duerme. Quizá sea ésta una manera un tanto paradójica por parte de Manent de abrir la sección dedicada a Wordsworth, puesto que es bien conocida la aversión que sentían tanto él como Coleridge hacia la vida urbana, que comparaban con una prisión. Sin embargo, en el poema, la ciudad es bella cuando todavía duerme y el aire está libre de humo ("smokeless"). Podría decirse que en este punto Manent deshistoriciza el texto, ya que "smokeless" es traducido por el más neutro "net" ('limpio'), con lo cual desaparece la crítica larvada a la contaminación habitual de la ciudad. El poema de Wordsworth es un soneto petrarquesco; el de Manent también, ya que está compuesto en decasílabos y usa la rima (aunque las rimas de los cuartetos no se corresponden del todo con las convencionales del soneto petrarquesco). ${ }^{7}$ De hecho, la parcialidad de Manent hacia el soneto (forma que Wordsworth, por otra parte, cultivó con asiduidad) se ve claramente reflejada en el hecho

\footnotetext{
${ }^{5}$ Los títulos de los poemas en inglés siguen la edición de Oxford University Press (1936) a cargo de Thomas Hutchinson, revisada por Ernest de Selincourt (Wordsworth 1936).

${ }^{6}$ En el caso de Coleridge, los títulos de los poemas en inglés están tomados de la edición de Penguin (1957) a cargo de Kathleen Raine (Coleridge 1957).

${ }^{7}$ Terry (1990: 119) califica la versión de este soneto de "brillante".
} 
de que, aparte del dedicado al puente de Westminster, la selección incluye cuatro más. El primero, "Pur element de l'aigua", se centra en un elemento de la naturaleza (el agua) que, aparte de ser esencial para la vida humana, produce también un efecto balsámico sobre el espíritu más allá de la muerte. Al final se subraya la armonía entre el mundo natural y el humano. En el segundo, "El barranc encantat", la voz poética se pregunta dónde ha ido a parar la música de los elfos que una vez danzaron en el barranco del título, música que puede verse como una fusión de lo natural y lo sobrenatural. El tercero, "Rectoria al comtat d'Oxford", subraya la sensación de unidad de lo sagrado y lo profano, ya que no existen lindes visibles entre ambos mundos. El mundo natural permite entrever, fugazmente, la eternidad. $Y$ en el cuarto, "Cementiri al sud d'Escòcia", la búsqueda de integración entre lo humano y lo natural hace que la conciencia perciba la alegría de la naturaleza incluso en el lugar menos idóneo: un cementerio. Una vez más se detecta el anhelo de armonía, de unidad, entre realidades aparentemente opuestas. $Y$ el tono de celebración de la naturaleza, como tantas otras veces. "By humble choice of plain old times" se traduce como "la bondat humil d'antany", añadiéndose así, quizá por razones métricas, un elemento moral que no se corresponde del todo con el original ('la bondad humilde de antaño'). Por otra parte, "verdes cicutes" ('verdes cicutas') por "hillocks green" parece fruto de una confusión de "hillocks" ('colinas') con "hemlocks" ('cicutas'). Más allá de detalles como éstos, el afán de unidad, de resolver tensiones y dicotomías, forma parte del núcleo temático de los cuatro sonetos. En cuanto a la forma del verso en la traducción, al contrario que en el dedicado al puente de Westminster, estos cuatro sonetos están compuestos en verso blanco (no rimado) y alternan los decasílabos con los alejandrinos. Adoptan, pues, una forma menos compacta que la del original. $^{8}$

Por otra parte, el poema que Manent titula "Llúcia" ('Lucía') representa, dentro de la selección de piezas de Wordsworth, el uso por los primeros románticos de la estrofa propia de la balada popular inglesa, cuya manifestación prototípica constaba de cuatro versos de los que el primero y el tercero eran tetrámetros (yámbicos o trocaicos), mientras que el segundo y el cuarto eran trímetros (también yámbicos o trocaicos) y además rimaban. Esta forma, sin embargo, puede verse sometida a distintas variaciones. Lo más singular de este poema traducido es que en él Manent ha unido dos poemas distintos de Wordsworth, llevando así el proceso de apropiación del que hablábamos antes un poco más lejos. El primer poema

\footnotetext{
${ }^{8}$ En este sentido, sorprende un poco la afirmación de Roser i Puig (1998: 25) según la cual cree "justificado atribuir la decisión de mantener la rima en las traducciones a la influencia del pensamiento romántico", puesto que en muchas traducciones Manent prescinde de la rima, aunque no del metro como principio regulador del lenguaje poético.
} 
habla de la muerte de Lucy; el segundo, del regreso de una muchacha a la naturaleza tras su muerte. Al unir ambos poemas, Manent hace que la primera experiencia vaya seguida de la segunda; es decir, que tras la muerte Llúcia vuelva a las piedras, los peñascos y los árboles, una afirmación con tintes panteístas. ${ }^{9}$ En cuanto a la forma del verso, Manent imita la estrofa de la balada pero a una cierta distancia: los versos impares pueden ser decasílabos $u$ octosílabos, mientras que los pares son a veces hexasílabos pero otras veces también octosílabos o decasílabos, y riman entre ellos con rima asonante (en los poemas originales de Wordsworth riman tanto los pares como los impares, según el esquema abab). Más adelante, cuando nos ocupemos de la "Rime of the Ancient Mariner", hablaremos con mayor detalle de la forma métrica y estrófica con la que traduce Manent la estrofa de la balada.

Finalmente, la selección de Manent incluye pasajes de poemas que Wordsworth escribió en verso blanco, es decir, en series de pentámetros yámbicos sin rima. Normalmente el poeta inglés utiliza el verso blanco en poemas narrativos extensos, como The Prelude, o en otros no tan extensos pero en los que predomina el tono meditativo. Los cuatro fragmentos de "EI Preludi" que incluye Manent nos permiten entrever lo que podría haber pasado si el poeta-traductor se hubiera decidido a verter el poema completo. No existe ninguna traducción íntegra de The Prelude al catalán, de modo que, leyendo los magníficos decasílabos de Manent, que fluyen de modo sosegado y utilizan un registro léxico quizá más parecido al de Wordsworth que el de otros poemas traducidos, el lector moderno no puede dejar de imaginarse el poema completo a partir de los fragmentos. En cuanto a la elección de los fragmentos concretos, las razones podrían hallarse una vez más en las afinidades temáticas: la inmortalidad del alma, la comunión espontánea de los niños con el espíritu de la naturaleza (cuando se resisten a volver a casa en las tardes de invierno), la percepción de la armonía por debajo de realidades discordantes, la vida de las personas sencillas en contacto con la naturaleza, lejos del ruido de las ciudades, etc.

El segundo poema de tono meditativo que incluye Manent en su selección es "Clarianes d'immortalitat en els records de la primera infantesa", una oda en la que se expone una visión de la inmortalidad del alma que tiene raíces tanto cristianas como platónicas. Como ya se ha comentado en la sección 2.1., el alma, cuando llega al mundo, viene de la eternidad, por lo que la infancia es el período en el que se encuentra más cerca de su origen. Luego, el paso de los años vuelve el recuerdo más

\footnotetext{
9 Según Roser i Puig (1998: 23), Manent se refiere el panteísmo, a la divinización de la naturaleza, como uno de los rasgos definitorios del primer Wordsworth.
} 
tenue y hace que el ser humano adulto se pregunte dónde ha quedado aquel "esplendor sobre la hierba". La manera de reconciliar estos dos opuestos (la intuición casi sagrada del niño y la caída en la rutina del adulto) consiste en advertir que el abismo que separa estos dos estadios de la experiencia humana no debe ser fuente de dolor, sino que debemos buscar en los rescoldos de un fuego que antes ardió intensamente la fuerza para vivir. Además, la comunión con la naturaleza es otro reflejo de ese estado anterior del alma, e incluso de su inmortalidad. La oda se compone de varias estrofas sin una forma fija, en la que varían tanto el número de versos como el patrón métrico. Consiguientemente, Manent utiliza también versos de diversa medida: alejandrinos, decasílabos, octosílabos, hexasílabos... Sin embargo, prescinde de la rima. Ahora bien, un aspecto que llama poderosamente la atención en esta traducción es que, a pesar de incluir la mayor parte del poema, no sea íntegra, puesto que omite algunas estrofas enteras $y$, por otra parte, une, en alguna ocasión, dos estrofas del original en una sola. Desclot (1988: 41-42) señala que el carácter fragmentario de muchas traducciones de Manent es comprensible en casos como el de The Prelude, por su extensión, pero no tanto en poemas como "Intimations of immortality", que ocupa poco más de doscientos versos. Desclot (ibidem) piensa que no cabe atribuir este hecho a la desidia o pereza del traductor, sino que

debemos considerar el fragmentarismo de tantas versiones de Manent como consecuencia de una búsqueda del texto esencial que conviene al poeta, no al antólogo profesoral. El poeta selecciona y recorta de una obra poética con la misma libertad desinhibida con la que escogería entre la abundancia de la realidad para un poema de otro como verdadero correlato objetivo de las propias emociones.

\subsubsection{Coleridge}

Gran parte de los comentarios que se han ido vertiendo a propósito de los poemas de Wordsworth traducidos por Manent es aplicable a los de Coleridge. Entre los incluidos en Poesia anglesa $i$ nord-americana enumerados más arriba, vamos a centrarnos en tres de ellos: "Gel a mitjanit", el fragmento de "Kubla Khan" y el "Poema del vell mariner".

"Gel a mitjanit" tiene un recorrido circular, ya que empieza con la observación del hielo a medianoche y termina con una nueva alusión al hielo, con una voz poética que goza de la calma y del silencio en un entorno rural. Todos en la casa duermen, excepto la voz poética, que se encuentra acompañada por su bebé, que duerme también plácidamente a su lado. Las reflexiones del yo poético pasan de su propia infancia, que transcurrió en una ciudad, a la infancia que imagina y desea para su hijo, en medio de la naturaleza, que hará que todas las estaciones sean felices para él. La 
traducción de Manent, muy fragmentaria, se limita a la última estrofa, compuesta por diez versos y centrada en esta felicidad indiscriminada que prevé para su hijo, más allá de los cambios estacionales, cuya esencia se recoge en los detalles. Es muy posible que fuera esto lo que captara el interés del traductor, esta felicidad más allá de las circunstancias juntamente con las circunstancias mismas, dotadas de una cualidad casi emblemática. Sin embargo, Manent formula como un deseo ("Que les estacions de l'any et siguin dolces") lo que en el original se contempla como un hecho; es decir, para el yo poético, la felicidad imaginada para el futuro niño que ahora no pasa de ser un bebé no será más que la consecuencia lógica de vivir en un entorno natural, en armonía con la naturaleza, en el seno de la cual verá y oirá

The lovely shapes and sounds intelligible

Of that eternal language, which thy God

Utters, who from eternity, doth teach

Himself in all, and all things in himself.

Great universal Teacher! he shall mould

Thy spirit, and by giving make it ask.

La relación de causalidad entre comunión con la naturaleza y felicidad, dotada de connotaciones claramente religiosas, se nos aparece aquí formulada de un modo más directo, podría decirse incluso que más ingenuo, que en Wordsworth, donde la tristeza afecta incluso a quien vive en estrecho contacto con lo natural. En cuanto a la forma, el poema original utiliza el verso blanco, con el pentámetro yámbico como patrón métrico, mientras que en el poema traducido alternan los decasílabos y los alejandrinos no rimados.

En "Kubla Khan", sin duda uno de los poemas más conocidos de Coleridge, el yo poético, después de describir la cúpula majestuosa construida por Kubla Khan, juntamente con el paisaje que la rodea (paisaje que, por cierto, adquiere un valor claramente simbólico, ya que conjuga los elementos domados y controlados por el hombre con aquellos otros salvajes que escapan a su control, en lo que algunos críticos han visto la dicotomía entre la parte racional y la irracional o subconsciente del ser humano), presenta en la última estrofa a la chica abisinia que toca el salterio como un símbolo de la imaginación creativa de los románticos, que literalmente conjura desde la ausencia física una realidad presente en el recuerdo. Manent traduce únicamente esta última estrofa, en la que el poema se refiere simbólicamente a la creación poética misma y a la naturaleza singular del poeta, un ser elegido cuyos dones no han sido repartidos de manera uniforme entre sus congéneres. No le interesa a Manent, en cambio, la dicotomía a la que nos hemos referido anteriormente, en su línea 
habitual de subrayar lo unitario, lo armónico, lo que permite superar las tensiones y las dicotomías. En cuanto a la forma poética, esta última estrofa del original está escrita con los ritmos de la balada tradicional, puesto que alterna los tetrámetros y los trímetros, normalmente con ritmo yámbico, pero sin ceñirse a la alternancia fija que prescribe la forma estrófica de la balada. Manent intenta acercar la medida de su verso a la del original, y así encontramos algunos hexasílabos y octosílabos; pero, por razones evidentes (y perfectamente audibles) de contraste fonométrico entre inglés y catalán, con mucha frecuencia debe recurrir al decasílabo e incluso, en alguna ocasión, al alejandrino. Finalmente, el original utiliza la rima, pero la traducción no lo hace.

"The Rime of the Ancient Mariner" es el poema que encabeza las Lyrical Ballads y en él Coleridge recrea una experiencia onírica de gran carga simbólica. El viejo marinero del título alteró el orden moral de la naturaleza al matar a un albatros en los mares helados al sur del Estrecho de Magallanes, haciendo descender de ese modo la desgracia sobre sí mismo y sobre toda la tripulación. Cuando quedó como único superviviente a bordo del barco, tuvo que vivir experiencias que le llenaron de angustia y de horror. Finalmente, una vez ha regresado ya a su pueblo natal, periódicamente siente la necesidad ineludible de contar su historia a algún extraño, y eso es exactamente lo que hace en la ocasión que da pie al poema. En cuanto a la forma del verso, ya hemos visto más arriba que la estrofa de la balada tradicional constaba de cuatro versos, los impares más largos y los pares más cortos y rimados. Las adaptaciones románticas de esta forma solían alternar los tetrámetros con los trímetros, aunque la forma es flexible y caben otras posibilidades. Coleridge, en este poema concreto, aún flexibiliza más la forma de la balada. Como dice el propio Manent (1982: 9) en el prólogo a la edición de 1982 de su traducción

\begin{abstract}
Este poema fue concebido partiendo del modelo de la balada popular, a veces un poco tosca, pero Coleridge modificó su estructura: las tradicionales estrofas de cuatro versos se alargaron, a veces hasta cinco, seis e incluso nueve versos, y la música se enriqueció con rimas internas, aliteraciones y asonancias. El viejo marinero es, sin embargo, un poema fiel a la esencia de la balada popular tal como la definió Ker: una pieza donde se mezclan la poesía narrativa y la poesía lírica. La extraña fabulación es como un sueño, es una historia de misteriosa locura.
\end{abstract}

Añade Manent (ibidem) que, si bien Coleridge no ha logrado todavía desembarazarse del todo de la dicción poética típica del siglo XVIII inglés, en muchos momentos del poema se nota la tendencia a servirse de un 
lenguaje más directo y sencillo, que, además, contribuye a realzar la atmósfera de misterio.

La importancia que Manent atribuye a este poema queda patente ya en el hecho de que el "Poema del vell mariner" sea el único (de Wordsworth o Coleridge) de una cierta extensión que no traduce de manera fragmentaria para la antología de 1955. A pesar de su longitud, lo traduce entero, y luego, casi treinta años más tarde (1982), vuelve a publicarse en forma de volumen independiente. En cuanto a las líneas de afinidad entre la poética 'manentiana' y el poema de Coleridge, podría citarse, por un lado, la fascinación ejercida por el relato del marinero, lleno de símbolos oníricos y transportado en las alas de una música hipnótica, y por otro, la interpretación del poema que él mismo suscribe, explícitamente, en el prólogo, que sin duda lo acerca a su visión del mundo. Nos lo dice en palabras de Brooke por él traducidas al catalán y aquí vertidas al castellano (Manent 1982: 11):

el mundo espiritual se inclina a la compasión y al amor, y los que violan estos sentimientos sufren como castigo el endurecimiento de corazón. No pueden rezar, no pueden poseer buen juicio, no pueden bendecir a los seres vivos de la tierra, del mar y del aire.

En cuanto a la forma del verso adoptada por el poema traducido de Manent, el tetrámetro inglés se convierte generalmente en catalán en un octosílabo, un decasílabo o un alejandrino, raramente en un verso más largo o más corto (aunque hay algunos hexasílabos); en cualquier caso, siempre en un verso con un número par de sílabas. El trímetro inglés, a su vez, se convierte en catalán en un hexasílabo, un octosílabo o un decasílabo; tampoco suele ser ni más largo ni más corto, y el número de sílabas del verso también es siempre par. Generalizando, se puede decir que el metro del poema original es anisosilábico, pero lo es de modo recurrente, ya que consiste en la alternancia de tetrámetros y trímetros, mientras que el anisosilabismo del poema traducido no es recurrente, sino altamente variable, lo cual contribuye a desfigurar en cierto modo el ritmo, muy dependiente de la regularidad métrica. Entiéndase esto no como una crítica al (por otra parte, excelente) resultado de la traducción de Manent, sino como una descripción de la diferencia entre poema original y traducido en términos métricos. La excelencia del intento se advierte de modo especial en el uso de la rima, que imita el del poema original y lo hace de un modo muy efectivo, ayudando a crear en cada estrofa la sensación de cierre, de unidad autocontenida, tan audible en el original.

Antes de poner punto final a esta sección dedicada a las traducciones realizadas por Manent de poemas de Wordsworth y Coleridge, puede resultar de interés comparar tanto el contenido como las opciones 
traductoras de Poesia anglesa i nord-americana con los de las otras dos antologías a las que nos hemos referido anteriormente. En Versions de l'anglès (1938) sólo se incluye un poema de Wordsworth (el soneto ya comentado "En el pont de Westminster") y dos fragmentos sueltos del "Poema del Vell Mariner". Tanto el primero como los segundos forman parte de la antología de 1955, como ya hemos visto, y lo hacen sin experimentar cambio alguno, aparte de leves correcciones ortotipográficas relacionadas con el uso de mayúsculas y minúsculas y con la puntuación. En El gran vent i les heures, la antología de 1983, vuelven a reproducirse el soneto de Wordsworth, también sin modificaciones, y los fragmentos del "Poema del Vell Mariner", con la curiosa incidencia de que hay una estrofa reescrita por completo, mientras que el resto permanece intacto. Manent añade a estos fragmentos un pasaje de otro poema de Coleridge que no aparecía en la versión de 1938: se trata de "Frost at midnight", del cual ya hemos visto que aparecía un fragmento en la antología de 1955, distinto del que se incorpora en 1983 bajo el título de "Però tu, el meu infant...". Cabe observar, en relación con la secuencia temporal de estas tres antologías, que parece darse una evolución hacia un grado más bajo de formalización poética con el paso del tiempo. Como se ha comentado más arriba, "En el pont de Westminster" es un soneto en decasílabos que usa la rima, mientras que otros sonetos comprendidos en Poesia anglesa $i$ nord-americana prescinden de la rima y combinan los decasílabos y los alejandrinos. En cuanto a los fragmentos del "Poema del Vell Mariner" incluidos en Versions de l'anglès, todas las estrofas muestran una estructura idéntica a la del original, con alternancia entre los octosílabos y los hexasílabos y rima entre los versos pares, mientras que la versión íntegra del poema tal como aparece en la antología de 1955 es mucho menos compacta, como ya se ha apuntado anteriormente, en el sentido de que muestra un anisosilabismo menos sistemático, con alternancia de versos de distintas medidas.

\section{WORDSWORTH Y COLERIDGE DESPUÉS DE MANENT: VILLANGÓMEZ, PARCERISAS,} DESCLOT

Algunos de los poetas-traductores más recientes no han dejado de acercarse a la poesía de los fundadores del romanticismo inglés, a pesar de los ilustres precedentes. Más bien al contrario, se observa que el hecho de que un poema ya hubiese sido traducido anteriormente parece actuar en ocasiones como acicate para una retraducción. Por ejemplo, el poeta ibicenco Marià Villangómez (1991), en el volumen de su obra completa dedicado a recoger las versiones de poemas en inglés, incluye un poema de Wordsworth y otro de Coleridge que ya habían sido traducidos por Manent. Se trata del soneto que Manent había titulado "Pur element de l'aigua" y del fragmento de la obra de teatro en verso Zapolya que Manent llamó "Cançó 
de Glicina" y que para Villangómez sería simplemente la "Cançó de Zapolya". Quizá lo más distintivo de las versiones de Villangómez sea la búsqueda de una forma externa lo más compacta posible. El soneto de Wordsworth traducido por Villangómez usa el alejandrino, pero también la rima, al contrario que Manent; la "Cançó de Zapolya", a su vez, intenta seguir de cerca el ritmo de la canción de Coleridge, para lo cual es esencial que el verso no se desparrame en unidades demasiado largas. Así pues, la traducción de Villangómez alterna el octosílabo con el hexasílabo y el tetrasílabo, mientras que Manent llegaba a introducir alejandrinos en su traducción. En cuanto al léxico, sin que haya diferencias extraordinariamente llamativas entre las versiones de Manent y de Villangómez, sí se observa en el último una tendencia a no distanciarse demasiado de la lengua común, con el fin, probablemente, de crear un efecto de mayor naturalidad.

Según Parcerisas (1998: 44), el interés que guía a Villangómez en su fértil labor como traductor de poesía radica en "los poemas individuales -aquellos ejemplos que lo han complacido o que le han supuesto un retoy no un proyecto editorial de encargo o una necesidad docente". Seguramente por ese motivo, sus colecciones de poesía traducida incluyen una nómina extensa de poetas, la mayoría de los cuales están representados por muy pocos poemas. En cuanto a la manera de abordar la traducción de la poesía ajena, Parcerisas (1998: 45) subraya que Villangómez muestra una gran coherencia al denominar sus antologías "versiones", puesto que lo que pretende es "una aproximación de intensidad, pero no una aspiración a una inútil 'fidelidad' a un original foráneo". Sin embargo, muchas de sus traducciones muestran una gran fidelidad tanto formal como de sentido. La relación que entabla un poema traducido con su original es una paleta llena de matices, difícilmente reductible a dicotomías como fiel / libre, que dicen muy poco y simplifican una cuestión en sí misma muy compleja. No tenemos espacio aquí para ahondar en este asunto. Sin embargo, no me resisto a citar a dos magníficos traductores, a la par que estudiosos de la traducción en el ámbito catalán, que se han pronunciado sobre el método traductor de Villangómez de un modo sutil, relativizando la dicotomía. Parcerisas (1998: 49) afirma que una relativa libertad formal del original no da siempre como resultado más libertad en el poema traducido, y viceversa, una forma estricta no pide una traducción "forzosamente rígida". Es decir, que todo depende de los recursos utilizados y de la posibilidad o no de utilizarlos en la lengua de llegada. Por su parte, Mallafrè (2004: 28) avanza de manera tentativa la hipótesis de que "Villangómez realiza una traducción más libre o se ajusta menos a la métrica o a la rima en algunos casos, y se acerca más cuanto más se identifica con el poema y sobre todo con la forma original", 
algo que, según le parece, es especialmente aplicable al soneto, una forma que Villangómez cultivó con asiduidad. Con todo, al igual que en el caso de Manent, estas afirmaciones se basan en análisis muy parciales de la poesía traducida del poeta ibicenco, puesto que no se dispone de estudios sistemáticos, que nos permitirían afinar más e ir más allá de los juicios impresionistas.

En 1985 ve la luz en la colección Les millors obres de la literatura universal, de Edicions 62, la antología titulada Poesia anglesa $i$ nordamericana. Del segle VIII al XIX, a cargo de Francesc Parcerisas. El antólogo dedica el volumen, precisamente, a Marià Manent y Marià Villangómez, y en la presentación (Parcerisas 1985: 9) justifica la inclusión de traducciones de otros autores al lado de las suyas propias diciendo que algunos poetas ingleses y norteamericanos ya han sido muy bien traducidos al catalán y, por tanto, sería "ocioso" volverlos a traducir. La antología incluye los siguientes poemas de Wordsworth: "Tintern Abbey" y un fragmento de The Prelude (traducidos ambos por Parcerisas), el soneto "Pur element de l'aigua" (en traducción de Villangómez) y los tres poemas traducidos por Folguera a los que se ha aludido más arriba (los dos titulados "Cançó" y el titulado "Març"). En cuanto a Coleridge, la selección incluye un fragmento de la tercera parte del "Poema del Vell Mariner" en traducción de Manent, la "Cançó de Glicina" traducida por Villangómez y el poema "Gebre a mitjanit" en traducción del propio Parcerisas. Este último poema ya había sido traducido por Manent con el título de "Gel a mitjanit", pero en este caso es evidente que a Parcerisas no le pareció "ocioso" volverlo a traducir. De hecho, una comparación del sentido de ambas traducciones arrojaría alguna diferencia importante, sobre todo por lo que respecta a la última estrofa, en la que la voz poética de Manent (como ya se ha visto más arriba) desea que todas las estaciones del año sean dulces para su hijo, que duerme a su lado, mientras que la de Parcerisas afirma que todas las estaciones serán dulces para él por el hecho de haber visto y oído "las formas bellas y los sonidos inteligibles / de este lenguaje eterno" que pronuncia el mismo Dios.

En cuanto a los "criterios de traducción", tal como los denomina el propio Parcerisas, él mismo nos da las claves de sus opciones formales (1985: 7):

El lector encontrará en las páginas que siguen poemas traducidos siguiendo una estructura métrica a menudo coja o laxa, y otros que no pretenden ser sino una versión literal, más o menos literaria, pero no ajustada a ningún patrón métrico. Estas divergencias obedecen a los mismos criterios subjetivos [invocados a la hora de justificar la selección de poemas]: a veces me ha parecido que, por torpes que fueran, las traducciones sólo podían hacerse en verso, porque gran parte de la gracia del original se encuentra en el ritmo. La solución 
ideal, que es la de leer los originales con una traducción fiel, verso a verso, a pie de página, era, aquí, imposible.

Los tres poemas de Wordsworth o Coleridge traducidos por Parcerisas responden exactamente a esta descripción. En el fragmento del Preludio y en "Gebre a mitjanit" no se sigue ningún patrón métrico; en "Tintern Abbey", tampoco, aunque es más frecuente encontrar versos decasílabos, alejandrinos o de otras medidas, lo cual dota al poema de mayor musicalidad. Por otra parte, hay que añadir que tanto el léxico como la gramática huyen del arcaísmo y del lenguaje deliberadamente poético, y consiguen crear, así, un efecto de gran naturalidad que podría considerarse en cierto modo análogo al que pretendían generar Wordsworth y Coleridge en su tiempo cuando invocaban la validez de la lengua común para fines poéticos. El léxico de Parcerisas busca sobre todo la precisión y el matiz, tan importante sobre todo en los poemas de tono reflexivo. La sintaxis, a su vez, se subordina a la claridad del argumento; como puede verse en algunas oraciones relativamente complejas de "Tintern Abbey", por ejemplo, las cláusulas subordinadas están perfectamente delimitadas, con el fin de evitar la posible ambigüedad, y la puntuación contribuye a la legibilidad del texto. Todo parece encaminado a hacer que emerja con claridad el sentido: la idea (presente en los tres poemas o fragmentos traducidos por Parcerisas) de la naturaleza como fuerza moral.

Finalmente, en 1986 aparece en la colección Llibres del Mall, de Edicions del Mall, L'abadia de Tintern $i$ altres textos, a cargo de Miquel Desclot. El volumen contiene el extraordinario poema del título y otros dos de Wordsworth: "A Night Piece" ("Nocturn") y "Nutting" ("En collir avellanes"), y se cierra con la "Advertencia" que encabeza la edición de 1798 de las Baladas líricas seguida del famoso prólogo a la edición de 1800, al que ya se ha hecho alusión más arriba. De hecho, según información proporcionada por el propio Desclot en la nota que precede las traducciones (1986: 21-22), "Tintern Abbey" fue traducido en 1982, y el poema traducido vio la luz por primera vez en 1985 , en el número 27 de la revista Reduccions. Debido a que su extensión era insuficiente para aparecer como volumen, el traductor pensó en añadir los prólogos en prosa ya mencionados y, más tarde, los otros dos poemas, que fueron traducidos en 1985. Además, para su publicación en formato de libro, "L'abadia de Tintern" fue revisado "a fondo" (Desclot 1986: 22). Posteriormente, estos tres poemas han sido recogidos, con ligeras modificaciones, en De tots els vents (Desclot 2004), una selección de las versiones poéticas realizadas por Desclot. Por lo tanto, la traducción de "Tintern Abbey" de Desclot es prácticamente coetánea de la de Parcerisas, puesto que ambas se publicaron por primera vez en 1985. Con estas traducciones se llenó un 
vacío importante en la obra de Wordsworth traducida al catalán, ya que "Tintern Abbey" es uno de los poemas centrales del canon wordsworthiano.

La razón de esta centralidad la explica de manera bien elocuente el propio Desclot en la nota que precede su traducción (1986: 24):

\begin{abstract}
Aunque no era la primera vez que Wordsworth tocaba el tema de las relaciones recíprocas entre el hombre y la naturaleza, en La Abadía de Tintern encontró el correlato objetivo ideal para desarrollarlo con amplitud e intensidad. Su veneración religiosa por la naturaleza, de un marcado panteísmo, con todas las consecuencias morales que él era capaz de derivar de ella, quedó caracterizada en este poema de una manera definitiva (poco tiempo después, con El preludio, retomaba el tema con resultados no menos felices), e inauguró así un sentimiento poético que había de ser central en todo el Romanticismo europeo y americano.
\end{abstract}

La elección del poema por parte de Desclot, pues, queda implícitamente justificada por estas palabras. Los otros dos poemas incluidos en el libro de 1986 responden a "la intención de dotar al conjunto de los tres poemas de un máximo de unidad temática, estilística e incluso cronológica" (Desclot 1986: 21). En cuanto a los criterios de traducción, hay que decir en primer lugar que la forma externa de los poemas traducidos sigue muy de cerca la de los originales, puesto que al verso blanco de Wordsworth replica con perfectos decasílabos catalanes también sin rima. Por otra parte, cabe señalar también que la dicción, sin ser artificiosa, contiene elementos nítidamente poéticos, no estrictamente asimilables a una lengua literaria basada en el habla. Sin embargo, esto no constituye un alejamiento esencial de la dicción del Wordsworth poeta, quien, a pesar de sus pronunciamientos, no se limitaba al léxico de las clases medias y bajas sencillamente porque no podía borrar de un plumazo la tradición que lo precedía. En cualquier caso, y dado que las versiones de "Tintern Abbey" realizadas por Parcerisas y Desclot aparecieron casi simultáneamente, sería un ejercicio estilístico interesante y quizá revelador compararlas desde el punto de vista del léxico utilizado, o, lo que es casi lo mismo, del grado de adscripción a un registro poético.

Como colofón a este apartado, reproducimos a continuación las palabras de dos críticos en las que se valora la traducción de Desclot. El primero es Jaume Medina (2003: 51-52, aunque el texto fue publicado originariamente en el diario Avui el 22 de octubre de 1986):

Los pentámetros de L'abadia de Tintern resuenan con toda la fuerza del original en nuestro decasílabo, donde el traductor ha sabido acomodar la tensión de los más de ciento cincuenta versos y mantener continuamente el tono a través de las frescas imágenes y de las 
palabras sencillas y concretas elegidas de una manera tan acertada entre las nuestras más puras. Al regresar con el poeta a aquel pasado originario, mítico, en el cual tuvieron lugar unas vivencias enriquecedoras que esperan siempre al fondo de la memoria el momento de volver a mostrar la vida misma en la diversidad de la creación, no puede uno sino sentirse atraído por aquel afán de elevación al recuerdo en su estado de lucha por la consecución de su propia pureza, es decir, de su propia identidad.

El segundo no es otro que Marià Manent, quien califica la traducción de Desclot de "perfecta" (2009: 150), para luego añadir (ibidem):

En el ondear del decasílabo, el poeta catalán nos da un eco admirablemente fiel de la música austera del gran romántico inglés. Gracias a la riqueza de su lenguaje y al dominio de la forma, Desclot ha podido resolver pasajes bien difíciles de un poema -el primeroque es, según Harold Bloom, "una historia en miniatura de la imaginación de Wordsworth".

No es extraño que Marrugat (2009: 69) se haya referido a Miquel Desclot como "el poeta que más explícitamente ha seguido la vía manentiana": el elogio sin reservas de Manent no deja dudas sobre las afinidades entre ambos.

\section{CONCLUSIÓN}

Las traducciones de poemas de Wordsworth y Coleridge por parte de poetas-traductores catalanes de distintas generaciones configuran una tradición rica en diversidad de concepciones y en matices. La secuencia formada por Folguera, López-Picó, Manent, Villangómez, Parcerisas y Desclot es mucho más que una enumeración: es una cadena cuya existencia misma depende del engarce de sus eslabones. $Y$ eso es, en definitiva, una tradición: una cadena. Volviendo sobre poemas que ya habían sido traducidos con anterioridad o pronunciándose mutuamente sobre los resultados de sus esfuerzos, estos traductores entablan un diálogo que, en lo referente a los dos primeros adalides del romanticismo inglés, dura ya casi un siglo. No todos poseen la misma relevancia, evidentemente: el hecho de que en este trabajo se haya dedicado mucho más espacio a Marià Manent que a los demás obedece sobre todo a su estatus dentro del canon de la literatura catalana contemporánea, pero también a su centralidad dentro de la tradición reciente, que le convierte en maestro de muchos poetas-traductores posteriores. En el caso de Manent, 
he intentado penetrar, aunque sea sólo un poco, en su habitus, ${ }^{10}$ en el sesgo de su mirada sobre el campo literario ( $\mathrm{y}$, más concretamente, poético) catalán, que está en la base tanto de la elección de los autores y los poemas como de la voz con la que nos habla desde sus traducciones. En los otros casos, no se ha profundizado tanto, pero sí se ha tratado de establecer relaciones mutuas con el fin de señalar la posición de cada traductor respecto a los demás. Todos ellos merecen, en tanto que traductores, mucha más atención de la que les han prestado hasta ahora los estudiosos. En cualquier caso, las luces de esta tradición poético-traductora relativamente rica se ven oscurecidas por algunas sombras, entre las cuales destacan el carácter fragmentario de algunas traducciones y el hecho de que muchos poemas notables e incluso imprescindibles no hayan sido nunca traducidos al catalán. La ausencia más conspicua es sin duda la de The Prelude, un poema esencial en la producción de Wordsworth que sólo ha dado lugar en catalán a algunos fragmentos sueltos vertidos por Manent o por Parcerisas. Queda, pues, mucho por hacer, tanto en el ámbito de la traducción al catalán como en el del estudio de las traducciones ya publicadas, en relación con dos poetas románticos tan cruciales como Wordsworth y Coleridge.

\section{REFERENCIAS BIBLIOGRÁFICAS}

BOURDIEU, Pierre, Las reglas del arte. Génesis y estructura del campo literario (trad. Thomas Kauf). Barcelona: Anagrama, 2002 / 1995.

CAsanova, Pascale, La República mundial de las Letras (trad. Jaime Zulaika). Barcelona: Anagrama, 1999.

Coleridge, Samuel Taylor, Poems and Prose (ed. Kathleen Raine). London: Penguin, 1957.

, Poema del vell mariner (trad. Marià Manent). Sant Boi de Llobregat: Edicions del Mall, 1982.

DESCLOT, Miquel, "Sobre el present recull». En: WORDSWORTH, William, L'Abadia de Tintern i altres textos, Barcelona, Edicions del Mall, 1986, pp. 21-26.

, «Marià Manent, poeta de la traducció». En: Reduccions, 37, 1988, pp. 38-44.

, De tots els vents. Selecció de versions poètiques. Manresa: Angle, 2004 .

FolgueRA, Joaquim, Traduccions i fragments. Barcelona: Publicacions de La Revista, 1921.

\footnotetext{
${ }^{10}$ Los términos campo y habitus se utilizan aquí, naturalmente, en el sentido que les da Pierre Bourdieu (por ejemplo 2002).
} 
LóPEZ-PICó, Josep Maria, Temes: exercicis de geografia lírica. Barcelona: Impremta Altés, 1928.

MALLAFRĖ, Joaquim, «Les traduccions de Marià Villangómez». En: INSTITUT D'ESTUDIS CATALANS (ed.), Marià Villangómez: sessió en memòria, Barcelona, Institut d'Estudis Catalans, 2004, pp. 27-31.

MANENT, Marià, «Pròleg». En: Coleridge, Samuel Taylor, Poema del vell mariner, Sant Boi de Llobregat, Edicions del Mall, 1982, pp. 7-11. , «Wordsworth traduït per Miquel Desclot». En: MARRUGAT, Jordi (ed.), Marià Manent i la traducció, Lleida, Punctum \& TRILCAT, 2009, pp. 150-152.

, Versions de l'anglès. Barcelona: Residència d'Estudiants, 1938.

Poesia anglesa i nord-americana. Barcelona: Alpha, 1955.

, El gran vent i les heures («Versions de l'anglès». Segona edició ampliada). Barcelona: Laertes, 1983 .

MARRUGat, Jordi, «Estudi introductori». En: MARRUGat, Jordi (ed.), Marià Manent i la traducció, Lleida, Punctum \& TRILCAT, 2009, pp. 9-71.

MedinA, Jaume, Lletres d'enguany $i$ d'antany. Barcelona: Biblioteca Serra d'Or, 2003.

MOLAS, Joaquim, Poesia catalana romàntica. Barcelona: Edicions 62, 1965.

ORTín, Marcel, La prosa literària de Josep Carner. Barcelona: Quaderns Crema, 1996.

PARCERISAS, Francesc, «Presentació». En: PARCERISAS, Francesc (ed.), Poesia anglesa $i$ nord-americana. Antologia del segle VIII al XIX, Barcelona, Edicions 62, 1985, pp. 7-9.

, «Marià Manent i la traducció». En: TRIAdú, J. et alii (eds.), Marià Manent, Barcelona, Institut de Ciències de l'Educació, 1989, pp. 1726.

«Les traduccions de Marià Villangómez». En: Quaderns. Revista de traducció, 1, 1998, pp. 39-52. (ed.), Poesia anglesa i nord-americana. Antologia del segle VIII al XIX. Barcelona: Edicions 62, 1985.

PegenAUTE, Luis, "La época romántica». En: LAFARGA, Francisco y Luis Pegenaute (eds.), Historia de la traducción en España, Salamanca, Ambos Mundos, 2004, pp. 321-396.

PeRICAY, Xavier y Ferran TOUTAIN, El malentès del noucentisme. Tradició $i$ plagi a la prosa catalana moderna. Barcelona: Proa, 1996.

Roser I PUIG, Montserrat, El llegat anglès de Marià Manent. Barcelona: Curial / Publicacions de l'Abadia de Montserrat, 1998.

SELLENT, Joan, "La traducció literària en català al segle XX: alguns títols representatius». En: Quaderns. Revista de traducció, 2, 1998, pp. 2332. 
TERRY, Arthur, «Marià Manent i la tasca del poeta-traductor». En: Revista de Catalunya, 40, 1990, pp. 117-129.

TOUTAIN, Ferran, "Traducció i models estilístics». En: GoNZÁLEZ, Soledad y Francisco LAFARGA (eds.), Traducció i literatura. Homenatge a Ángel Crespo, Vic, EUMO Editorial, 1997, pp. 63-72.

VILLANGÓMEZ, Marià, Obres completes. Versions de poesia (1): Versions de l'anglès. Barcelona: Columna, 1991.

WORDSWORTH, William, Poetical Works (ed. Thomas Hutchinson y Ernest de Selincourt). Oxford: Oxford University Press, 1936.

, L'Abadia de Tintern $i$ altres textos (ed. y trad. Miquel Desclot). Barcelona: Edicions del Mall, 1986.

William y Samuel Taylor COLERIDGE, Baladas líricas (eds. y trads. Santiago Corugedo y José Luis Chamosa). Madrid: Cátedra, 1990. 